\title{
Functional tooth units and masticatory ability in elderly population
}

\author{
Fatimah Rini Dwiningrum¹, Kartika Indah Sari ${ }^{*}$, Rasmi Rikmasari² \\ ${ }^{1 * D e p a r t m e n t}$ of Oral Biology, Faculty of Dentistry Universitas Padjadjaran, Indonesia \\ ${ }^{2}$ Department of Prosthodontics, Faculty of Dentistry Universitas Padjadjaran, Indonesia
}

\begin{abstract}
Introduction: The elders are the ones that most often experience tooth loss which affects masticatory function. Masticatory function can be evaluated subjectively through masticatory ability assessment. The masticatory function is influenced by the number of posterior occluding pairs; this also may be called as functional tooth units (FTUs). The purpose of this study was to describe FTUs and masticatory ability in the elderly. Methods: This research was a descriptive study with a cross-sectional study design. Subjects were taken by purposive sampling technique. The study was conducted in the Lebakgede Subdistrict, Bandung City. Data mentioned were obtained by conducting interviews regarding data on subject characteristics and questionnaires of masticatory ability, as well as examining the oral cavity to obtain FTUs data. Results: Subjects obtained were 74 people consisting of 63 women $(85.14 \%$ ) and 11 men $(14.86 \%)$. Based on the results, the average age of the research subjects was 68.49 years, and those with good masticatory ability status were 26 elderly (35.14\%) with an average FTU value of 5.9 while 48 elderly $(64.86 \%)$ had poor masticatory ability status with an average FTU score of 1.5 , even 31 subjects (41.89\%) had a zero FTU score. Conclusion: The majority of the elderly in this research mostly had a low total FTUs score which means that the masticatory ability status in the elderly tended to be poor.
\end{abstract}

Keywords: Functional tooth units (FTUs); masticatory ability; elderly

p-ISSN: 1979-0201; e-ISSN: 2549-6212; Available from: http://jurnal.unpad.ac.id/pjd/article/view/29933

DOI: 10.24198/pid.vol33no2.29933

Submission: Okt 21, 2021; Accepted: Nov 29, 2021; Published online: Nov 30, 2021

\section{INTRODUCTION}

The distribution of the elderly population in Indonesia has doubled during the last five decades (1971-2017). The number of the elderly population is predicted to reach 10 percent of Indonesia's total population by 2021. The high number of elderly population will have an impact on several health problems that must be faced. ${ }^{1}$
The main problem of the health aspects faced by the elderly during the aging process are physical and functional changes that may cause disorders. Diseases that commonly found in the elderly were cardiovascular disorders, cancer, diabetes mellitus, hypertension, changes in cognitive function, even multiple chronic conditions can be experienced simultaneously. ${ }^{2}$ The elderly also experience a change in health perception in which

Corresponding author: Kartika Indah Sari, Department of Oral Biology, Faculty of Dentistry Universitas Padjadjaran, Indonesia. Jalan Sekeloa Selatan I, West Java, Indonesia, 40132. Phone: +62 852-6316-7939; Email: kartika.sari@fkg. unpad.ac.id 
the perceived condition of the elderly does not match the actual health status experienced due to their tendency to compare their personal health status with others in their respective age. ${ }^{3}$

The oral health condition of the elderly also deteriorated. These conditions include severe periodontal infection, complaints of dry mouth, increased caries prevalence, and severe tooth loss. 4,5 According to the 2018 Indonesian Basic Health Research (Riskesdas), the elderly age group is the age group that has the most tooth loss due to caries. ${ }^{6}$ Such conditions impacts quality of life and reduce the masticatory function in the elderly. ${ }^{4,7}$

Mastication is a complex motor activity to comminute food so that it could be swallowed and digested. ${ }^{8}$ Masticatory function can be evaluated objectively and subjectively. Objectively, the masticatory function is assessed by analyzing the masticatory performance. Masticatory performance is described as a person's capability to comminute test food into smaller particles under standardized testing conditions..$^{8,9}$ Method that is commonly used to measure masticatory performance is by measuring the size of test food particles that have been chewed (Sieving method). Another alternative method is by measuring the mixing degree of boluses by using test food such as two color changeable chewing gum (mixing method). ${ }^{10,11}$

Masticatory function is subjectively evaluated through the masticatory ability assessment. Masticatory ability is defined as an individual's perception of their ability to chew and comfort during chewing. ${ }^{9,12}$ One of a common method implemented in order to measure masticatory ability is by using a structured questionnaire containing questions regarding the health status of the oral cavity and dietary selection.

Subjective evaluation may provide the assessment to other factors in mastication such as adaptability, psychological condition, and individual health perception.9,13 Teeth and its purpose of breaking down food into smaller fragments, could be considered as an important component in the masticatory system. ${ }^{14}$ This process depends on the distribution of teeth and the total of occlusal contact that exists. Chewing problems usually increase as the posterior functional teeth are reduced and the remaining teeth are not well-distributed. . $^{73,15,16}$ Study conducted by Hsu et al. ${ }^{17}$ stated that patients with fewer remaining number of functional tooth units, tend to have poor masticatory ability. The purpose of this study was to determine the effect of the functional tooth unit on the masticatory ability of the elderly, so that it will be the basis for the importance of preventing tooth loss.

\section{METHODS}

\section{Subjects}

This research was a descriptive study with a crosssectional study design. The study was carried out from November 2019 through January 2020. The research sample was obtained from the elderly population aged $\geq 60$ years in Lebakgede Subdistrict, Coblong District, Bandung City. Subjects were taken by purposive sampling technique. Subjects who were unable to communicate well, have hearing loss, and neurological disorders: cerebral palsy, Parkinson disease, brain injury and brain trauma were excluded. We examined 77 participants. Three people were excluded because they had neurological disorders, resulting in 74 participants who signed the informed consent and completed the research procedures. Ethical exemption of this study was reviewed and approved by The Research Committee Universitas Padjadjaran Bandung (No. 1297/UN6.KEP/ EC/2019).

\section{Socio-demographic characteristic}

Subjects were asked by operators regarding data on the subject's characteristics: name, address, date of birth, age, gender, highest level of education, presence of dental prosthesis, systemic diseases: diabetes mellitus, cardiovascular diseases, neurological disorders, and smoking history. All data was recorded on the questionnaire form. ${ }^{18}$

\section{Masticatory ability}

Masticatory ability was measured using the questionnaire of "Panduan Pengisian Alat Ukur Kemampuan Mastikasi Bagi Dokter Gigi/Guideline for filling out the measurement of masticatory ability for dentist" by Hanin et al. ${ }^{12}$ This has proven its validity and reliability. This questionnaire consisted of eight questions, in which " 0 " was 
the smallest score and " 3 " as the largest score per question. Subjects categorized as having good masticatory ability had a total score of items of $\geq 12$ and subjects categorized with poor masticatory ability had total score of items of < 12. The completion of this questionnaire was done by interviewing the subjects.

\section{Functional tooth units (FTUs)}

FTUs were defined as pairs of opposing posterior teeth, both natural teeth (sound, restored or carious teeth with D1-D4 scale: D1 described as enamel caries lesion without cavity, D2 described as enamel caries with cavity, D3 described as dentinal caries, D4 described as lesion with pulp involvement) and prosthetic teeth (fixed or removable denture). Missing teeth without prosthetic replacement, teeth with extensive coronary destruction, grade III mobility, and sensitivity to percussion test were categorized as non-functional. Two opposing premolars were rated as one FTU and two opposing molars were rated as two FTUs. Thus, subjects with complete dentition had 12 FTUs. FTUs were further categorized by tooth composition: NN-FTUs (natural tooth against natural tooth), ND-FTUs (natural tooth against denture), and DD FTUs. Third molars were excluded in this study. Clinical examinations were performed to determine subject's FTUs. ${ }^{15,16,19,20}$

\section{Clinical examinations}

Operators had been trained and calibrated before performing examinations on subjects' dental status. Subjects were instructed to sit on the chair provided, to open their mouth and to occlude their teeth. Operators were retracting buccal mucosa using a mouth mirror to identify contacts of the posterior teeth. Subjects with removable dentures were instructed to use theirs during examination. Subject's dental status recorded on the examination form. Items recorded were: functional teeth, non-functional teeth, teeth that were sensitive to percussion test, teeth mobility, and dental prosthesis type (if any).

\section{RESULTS}

Table 1. Respondents' characteristics

\begin{tabular}{|c|c|c|}
\hline Variables & n (total=74) & $\%$ \\
\hline \multicolumn{3}{|l|}{ Age } \\
\hline $60-69$ years & 47 & 63.51 \\
\hline 70 - 79 years & 22 & 29.73 \\
\hline$\geq 80$ years & 5 & 6.76 \\
\hline \multicolumn{3}{|l|}{ Gender } \\
\hline Woman & 63 & 85.14 \\
\hline Men & 11 & 14.86 \\
\hline \multicolumn{3}{|l|}{ Educational level } \\
\hline No formal education & 5 & 6.76 \\
\hline Not-graduated from elementary school & 10 & 13.51 \\
\hline Elementary school graduates & 38 & 51.35 \\
\hline Junior high-school graduates & 9 & 12.16 \\
\hline High-school graduates & 7 & 9.46 \\
\hline University degree & 5 & 6.76 \\
\hline \multicolumn{3}{|l|}{ Prosthetic rehabilitation } \\
\hline Present & 14 & 18.92 \\
\hline Absent & 60 & 81.08 \\
\hline \multicolumn{3}{|l|}{ Smoking history } \\
\hline Former smoker & 4 & 5.40 \\
\hline Smoker & 5 & 6.76 \\
\hline Non-smoker & 65 & 87.84 \\
\hline \multicolumn{3}{|l|}{ Systemic diseases } \\
\hline Present & 58 & 78.38 \\
\hline Absent & 16 & 21.62 \\
\hline
\end{tabular}


Table 1 showed that most subjects were categorized at 60-69 years of age. The youngest subject in this study was 60 years old while the oldest was 85 years old with 68.49 years of age on average. Nearly all the subjects in this study were women $(85.14 \%)$ and most subjects in this study were non-smoker $(87.84 \%)$. Fourteen out of 74 subjects $(18.92 \%)$ were using removable dentures.

The majority of elderly in this study had systemic disease (78.38\%) and half of subjects in this study were elementary school graduates (51.35\%).

Table 2. Mean number of functional tooth units among masticatory ability category

\begin{tabular}{|c|c|c|c|c|c|c|c|}
\hline \multirow[b]{2}{*}{ Masticatory Ability } & \multirow[b]{2}{*}{ n (\%) } & \multicolumn{6}{|c|}{ Mean ( $\sigma$ / Standard Deviation) } \\
\hline & & Teeth present & $\begin{array}{c}\text { Posterior } \\
\text { teeth present }\end{array}$ & Total-FTUs & NN-FTUs & ND-FTU & DD-FTUs \\
\hline $\begin{array}{c}\text { Good } \\
\text { (total score of items } \geq 12 \text { ) }\end{array}$ & $\begin{array}{c}26 \\
(35.14 \%)\end{array}$ & $\begin{array}{c}17.5 \\
( \pm 9.89)\end{array}$ & $\begin{array}{c}8.9 \\
( \pm 5.50)\end{array}$ & $\begin{array}{c}5.9 \\
( \pm 3.87)\end{array}$ & $\begin{array}{c}4.3 \\
( \pm 4.09)\end{array}$ & $\begin{array}{c}0.7 \\
( \pm 1.76)\end{array}$ & $\begin{array}{c}0.9 \\
( \pm 2.98)\end{array}$ \\
\hline $\begin{array}{c}\text { Poor } \\
(\text { total score of items }<12)\end{array}$ & $\begin{array}{c}48 \\
(64.86 \%)\end{array}$ & $\begin{array}{c}9.0 \\
( \pm 7.07)\end{array}$ & $\begin{array}{c}5.5 \\
( \pm 3,78)\end{array}$ & $\begin{aligned} & 1.5 \\
&( \pm 2.59)\end{aligned}$ & $\begin{array}{c}1.1 \\
( \pm 2.08)\end{array}$ & $\begin{array}{c}0.2 \\
( \pm 0.62)\end{array}$ & $\begin{array}{c}0.2 \\
( \pm 1.30)\end{array}$ \\
\hline
\end{tabular}

The total contact of molar pairs was most frequent in the right second molar, which are 18 contacts. The total contacts of premolars were most frequent in the left first premolar, which are 33 contacts and it was the highest number of teeth contact in this study. The distribution of the posterior tooth contacts we display is visualized in the graph below:

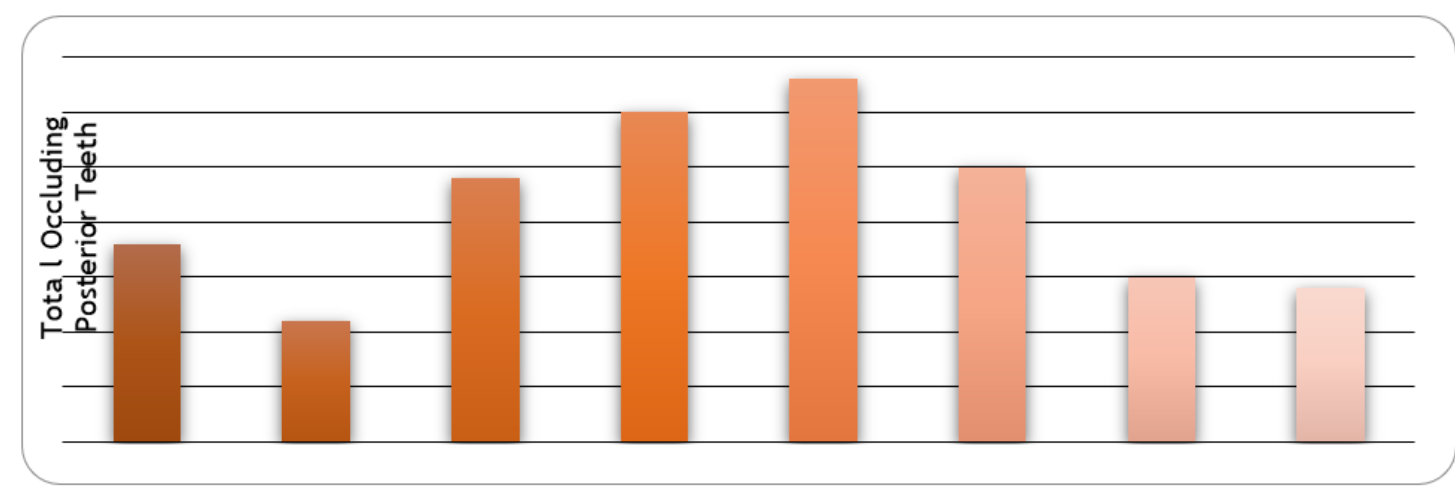

Figure 1. Posterior tooth contact distribution

Table 3. Subject's total ftus frequency

\begin{tabular}{ccc}
\hline Total-FTUs & Frequency $(\mathrm{n}=\mathbf{7 4})$ & Percentage $(\mathrm{n}=100 \%)$ \\
\hline 7 & 3 & 4.05 \\
8 & 3 & 4.05 \\
9 & 2 & 2.70 \\
10 & 1 & 1.35 \\
11 & 3 & 4.05 \\
12 & 3 & 4.05 \\
\hline
\end{tabular}

\section{DISCUSSION}

Masticatory problems usually appear concomitant with the loss of functional posterior tooth and in condition where remaining teeth were not welldistributed. Results of this study showed that the elderly who have good mastication ability were 26 elderly (35.14\%) and 48 elderly (64.86\%) had poor mastication ability status. The mean number of total-FTUs score in elderly with good masticatory ability status was 5.9 (Table 2). This finding was in accordance with both studies by Sheiham et al. ${ }^{21}$ and Sarita et al. ${ }^{22}$ which stated that difficulty in chewing food can be avoided by maintaining five pairs of occluded posterior teeth (5-6 total FTUs). ${ }^{21,22}$ However, this value was lower compared to the studies conducted by Ueno et al..$^{18}$ in Japan, Hsu et al. ${ }^{17}$ in Taiwan and Samnieng et al. ${ }^{23}$ in Thailand which stated sufficient masticatory ability can be achieved by maintaining 10 total- 
FTUs. ${ }^{17,23}$ Different results of FTUs might be caused by selection of subjects, number of subjects and several different sampling methods were used on subjects. All of the prior stated reasons might trigger the different FTUs results. Studies that include majority subjects with a high number of FTUs will have a high average number of totalFTUs. On the contrary, studies including majority subjects with low number of FTUs and had massive tooth loss will have low average number of totalFTUs. ${ }^{15}$

The elderly who used dentures in this study were only 14 people $(18.92 \%)$ and all of them used removable dentures. Good masticatory ability groups had higher mean numbers of ND-FTUs and DD-FTUs as shown in table 2 . The results obtained was consistent with study conducted by Zhang et $a .^{26}$ to 512 elderly people in China which stated that replacing missing teeth with removable dentures might compensate the masticatory ability impairment. ${ }^{24}$ However, some studies stated that removable dentures were not equal to natural teeth in restoring impaired masticatory ability. This is due to patients with natural teeth contacts would have higher bite force compared to those with dentures..$^{25}$ This might also happens due to limitations present in removable dentures e.g. lack of retention, adaptation, and stability. ${ }^{13,19,26}$

The majority of removable denture wearers in this research claimed that the conditions of their removable dentures were in decent quality, as they still maintain their comfortability during usage as well as no distinct functionality drawbacks. Elders' perceived convenience of their removable denture might be influenced by patient's perceptions on their oral health status, attitudinal factors and patient's motivation. Elderly also tends to compare their oral health status with another people in their ages and perceived their oral health condition in positive manners. ${ }^{3,27}$ Even so, dentist should recommend using removable or fixed dental prostheses in elders with massive tooth loss to regain posterior tooth contact and preserve their masticatory function. ${ }^{28}$

To rehabilitate masticatory ability, using implant-supported prostheses as tooth replacement is better than using removable denture. However, the patient's economic background must be considered. ${ }^{29,30}$ Furthermore, many aspects should be taken into account prior implant placement in elderly. Elderly tend to have systemic conditions which are commonly associated with aging such as diabetes, osteoporosis and cardiovascular diseases. Dental implant procedure may not be suitable in elderly with these conditions due to lack of bone density, deterioration in immune system and affect the wound healing process. In conditions where patients has Parkinson's diseases, cognitive function impairment, rheumatic diseases, etc. should also necessarily be considered since these diseases may interfere maintenance after surgery. ${ }^{31,32}$ Avoiding the use of removable dentures by maintaining posterior natural teeth as many as possible is the key to preserve masticatory function. ${ }^{12}$

Age did not influence masticatory ability as long as the elderly can maintain occluded posterior teeth or rehabilitate them as explained in the studies by Samnieng et al. ${ }^{23}$ Marito et al. ${ }^{33}$ A study conducted by Hsu et al. ${ }^{17}$ also stated that keeping as many natural teeth and occlusal contacts as possible would lower the risk of masticatory dysfunctions due to aging. ${ }^{9,17}$

Smoking was one of the main risk factors of periodontal disease. ${ }^{34}$ This habit had a long-term effect on cases of tooth loss. A study by Feizi et al. ${ }^{35}$ stated that smokers had worse masticatory ability than non-smokers. ${ }^{35}$ Study conducted by Rech et al. ${ }^{36}$ to 48 subjects in Brazil also showed that smokers had lower masticatory ability than non-smokers. It was found that smokers had more cases of tooth loss, carious lesions, and periodontal disease. ${ }^{36}$ Smoking cessation might have a good impact on oral health. Former smokers had a lower risk of tooth loss compared to someone who still smokes. The risk of tooth loss in former smokers was reduced after cessation, it might be almost had the same degree when compared with non-smokers after \pm 10 - 20 years of cessation. ${ }^{37-39}$

Table 3 has shown that the total-FTUs score of " 0 " was the total-FTUs score that most frequently appears in the subjects. Thirty one $(41.89 \%)$ of 74 subjects had a total-FTUs score of zero. This illustrates that the majority of the subjects in the Lebakgede Sub-district did not have posterior teeth contacts. Some subjects in this study even had good masticatory ability despite their total-FTUs score being zero or close to zero. The possible cause was that the elderly considered 
tooth loss as part of aging that was bound to occur so that the subject accepted their edentulous state and could maintain a positive perception of their oral health. ${ }^{3}$ Another possibility were that the elderly adapting to their tooth loss conditions and mastication process (e.g. unilateral side chewing)..$^{40}$ The elderly also adapt by increasing the number of mastication cycles. Every ten years or so, the mastication cycles increases around three cycles per swallowing. ${ }^{41}$

In this study, $78.38 \%$ of subjects had systemic disease. Systemic diseases such as diabetes and cardiovascular disorders could increase the risk of tooth loss. Yoo et al. ${ }^{42}$ conducted a cohort study and demonstrated that diabetes severity increased the risk of tooth loss. The study by Haq et al. ${ }^{43}$ also showed that the DMF-T and DMF-S scores in patients with cardiovascular disorders were higher than in the normal group, which suggests that systemic conditions could increase the risk of having poor oral health. ${ }^{43}$ Patients with no systemic disease tend to had more functional teeth and good masticatory ability. ${ }^{44}$

Moreover, this research has shown that contacts between premolar teeth are more frequent than molar as visualized in Figure 1. The cause is probably because the molar teeth were the first erupted teeth, specifically the first maxillary and mandibular first molars at the age of 6-7 years. ${ }^{45}$ Thus, the caries risk in molar teeth were higher than in other teeth. Second molars also had higher caries risk because of its unfavorable position and made it more difficult to clean the teeth. A study conducted by Upadhyaya et al. ${ }^{46}$ of 626 patients in Nepal stated that the frequency of tooth extraction caused by caries most often occurs in the lower first molar, then the maxillary first molar. The results showed that $80 \%$ of the extracted teeth were first, second, and third molars. ${ }^{46}$

The high frequency of zero total-FTUs scores in subjects showed that the subjects in Lebakgede Sub-district might have low awareness of the importance of maintaining occlusal contact or rehabilitating it. Some studies have shown that groups with higher levels of education have more occlusal contacts than groups with lower levels of education. ${ }^{17,26}$ This also indicates low oral health knowledge in subjects which is likely to be influenced by the subject's educational level with a percentage of $51.35 \%$ were only elementary school graduates (Table 1). Previous studies stated that subjects with higher level of education were more likely to have higher level of oral health knowledge. ${ }^{47,48}$

Weaknesses of this study were homogeneous samples so that the proportion of the sample was inequitable and less varied. Researcher's and subject's limitations, in particular, fatigue in conducting interviews, could also cause results bias. Further research with a larger sample is needed so that the population background would more vary and to avoid bias. Dentists should educate patients on oral health and encourage patients to maintain as many natural teeth as possible or replace them with prostheses if the teeth are lost so that the masticatory function is well preserved.

\section{CONCLUSION}

The majority of the elderly in this research mostly had a low total FTUs score which means that the masticatory ability status in the elderly tended to be poor.

\section{REFERENCES}

1. Sub-directorate of Education Statistics and Social Welfare. Elderly Population Statistics 2017. Jakarta: Central Bureau of Statistics; 2017. 3-5 p.

2. Jaul E, Barron J. Age-related diseases and clinical and public health implications for the 85 years old and over population. Front Public Heal. 2017; 5(12): 1-7. DOI: 10.3389/ fpubh.2017.00335.

3. Henchoz K, Cavalli S, Girardin M. Health perception and health status in advanced old age: A paradox of association. J Aging Stud. 2008; 22(3): 282-90.

4. Gil-Montoya JA, de Mello ALF, Barrios R, Gonzalez-Moles MA, Bravo M. Oral health in the elderly patient and its impact on general well-being: A nonsystematic review. Clin Interv Aging. 2015; 10(5): 461-7. DOI: 10.2147/CIA. S54630.

5. Kassebaum NJ, Bernabé E, Dahiya M, Bhandari B, Murray CJL, Marcenes W. Global burden of severe tooth loss: a systematic review and 
meta-analysis. J Dent Res. 2014; 93(7): 20-28. DOI: $10.1177 / 0022034514537828$.

6. Indonesian Ministry of Health. National Report on Basic Health Research. Indonesian Ministry of Health. Jakarta: Health Research and Development Agency; 2018. 199-210 p.

7. Dhingra S, Rajesh G, Rao A, Pai U, Shenoy R, Pai M. Impact of occlusal support and perceived chewing ability on oral health-related quality of life among patients attending a private dental institution in India. J Indian Prosthodont Soc. 2017 ; 17(1): 15-21. DOI: 10.4103/09724052.194943

8. Driscoll CF, Freilich MA, Guckes $A D$, Knoernschild KL, Mcgarry TJ, Goldstein G, et al. The glossary of prosthodontic terms. 9th ed. J Prosthet Dent. 2017; 117(5): e56. DOI: 10.1016/j.prosdent.2016.12.001.

9. Van der Bilt A. Assessment of mastication with implications for oral rehabilitation: a review. J Oral Rehabil. 2011; 38(10): 754-80. DOI: 10.1111/j.1365-2842.2010.02197.x.

10. Elgestad Stjernfeldt $P$, Sjögren $P$, Wårdh I, BoströmAM. Systematic review of measurement properties of methods for objectively assessing masticatory performance. Clin Exp Dent Res. 2019; 5(1): 76-104. DOI: 10.1002/cre2.154.

11. Tarkowska A, Katzer L, Ahlers MO. Assessment of masticatory performance by means of a color-changeable chewing gum. J Prosthodont Res. 2017; 61(1): 9-19. DOI: 10.1016/j. jpor.2016.04.004.

12. Aimaijiang $\mathrm{Y}$, Otomaru T, Taniguchi $\mathrm{H}$. Relationships between perceived chewing ability, objective masticatory function and oral health-related quality of life in mandibulectomy or glossectomy patients with a dento-maxillary prosthesis. J Prosthodont Res. 2016; 60(2): 92-7. DOI: 10.1016/j. jpor.2015.07.005.

13. Naka O, Anastassiadou V, Pissiotis A. Association between functional tooth units and chewing ability in older adults: a systematic review. Gerodontology. 2014; 31(3): 166-77. DOI: 10.1111/ger.12016.

14. Nelson SJ. Wheeler's Dental Anatomy, Physiology, and Occlusion. $10^{\text {th }}$ Ed. St. Louis, Missouri: Elsevier Saunders; 2015. 251-264 p.

15. Indrasari M, Dewi RS, Rizqi AA. The influence of the number of functional tooth units (FTUs) on masticatory performance. J Int Dent Med Res. 2018; 11(3): 982-7.

16. Ueno $M$, Yanagisawa $T$, Shinada $K$, Ohara $S$, Kawaguchi $Y$. Category of functional tooth units in relation to the number of teeth and masticatory ability in Japanese adults. Clin Oral Investig. 2010; 14(1): 113-9. DOI: 10.1007/s00784-009-0270-8.

17. Hsu KJ, Yen YY, Lan SJ, Wu YM, Chen CM, Lee $\mathrm{HE}$. Relationship between remaining teeth and self-rated chewing ability among population aged 45 years or older in Kaohsiung City, Taiwan. Kaohsiung J Med Sci. 2011; 27(10): 457-65. DOI: 10.1016/j.kjms.2011.06.006.

18. Agency for Health Research and Development. PTM Cohort Questionnaire. Jakarta: Ministry of Health of the Republic of Indonesia; 2011. p. 1-15.

19. Ueno M, Yanagisawa T, Shinada K, Ohara S, Kawaguchi Y. Category of functional tooth units in relation to the number of teeth and masticatory ability in Japanese adults. Clin Oral Investig. 2010; 14(1):113-9. DOI: 10.1007/s00784-009-0270-8.

20. Adiatman M, Ueno M, Ohnuki M, Hakuta C, Shinada K, Kawaguchi $Y$. Functional tooth units and nutritional status of older people in care homes in Indonesia. Gerodontology. 2013; 30(4): 262-9. DOI: 10.1111/j.17412358.2012.00673.x.

21. Sheiham A, Steele J. Does the condition of the mouth and teeth affect the ability to eat certain foods, nutrient and dietary intake and nutritional status amongst older people? Public Health Nutr. 2001; 4(3): 797-803. DOI: 10.1079/phn2000116.

22. Sarita PTN, Witter DJ, Kreulen CM, Van't Hof MA, Creugers NHJ. Chewing ability of subjects with shortened dental arches. Community Dent Oral Epidemiol. 2003; 31(5): 328-34. DOI: 10.1034/j.1600-0528.2003.t01-1-00011.x.

23. Samnieng $P$, Ueno $M$, Shinada $K$, Zaitsu T, Wright FAC, Kawaguchi Y. Oral health status and chewing ability is related to mini-nutritional assessment results in an older adult population in Thailand. J Nutr Gerontol Geriatr. 2011; 30(3): 291-304. DOI: 10.1080/21551197.2011.591271.

24. Zhang Q, Witter DJ, Bronkhorst EM, Creugers NHJ. The relationship between masticatory 
ability, age, and dental and prosthodontic status in an institutionalized elderly dentate population in Qingdao, China. Clin Oral Investig. 2019; 23(2) 633-40. DOI: $10.1007 /$ s00784-018-2477-z.

25. Manzon L, Vozza I, Poli O. Bite force in elderly with full natural dentition and different rehabilitation prosthesis. Int $\mathrm{J}$ Environ Res Public Health. 2021; 18(4): 1-12. DOI: 10.3390/ijerph18041424.

26. Hildebrandt GH, Dominguez BL, Schork MA, Loesche WJ. Functional units, chewing, swallowing, and food avoidance among the elderly. J Prosthet Dent. 1997; 77(6): 588-95. DOI: 10.1016/s0022-3913(97)70100-8.

27. Razak PA, Richard KMJ, Thankachan RP, Hafiz KAA, Kumar KN, Sameer KM. Geriatric oral health: a review article. J Int Oral Heal. 2014; 6(6): 110-6.

28. Khairani F, Fardaniah S, Mursid S. The relationship between socio-demographics and the location of missing teeth with type of prosthetic treatment decisions. J Int Dent Med Res. 2018; 11(3): 1002-6.

29. Kutkut A, Bertoli E, Frazer R, Pinto-Sinai G, Fuentealba Hidalgo R, Studts J. A systematic review of studies comparing conventional complete denture and implant retained overdenture. J Prosthodont Res. 2018; 62(1): 1-9. DOI:10.1016/j.jpor.2017.06.004.

30. Rismanchian M, Bajoghli F, Mostajeran Z, Fazel A, Eshkevari Ps. Effect of implants on maximum bite force in edentulous patients. J Oral Implantol. 2009; 35(4): 196-200. DOI: 10.1563/1548-1336-35.4.196.

31. Sato Y, Kitagawa N, Isobe A. Current Consensus of Dental Implants in the Elderly-What Are the Limitations? Curr Oral Heal Reports. 2020; 7(3): 321-6. DOI: $10.1007 / \mathrm{s} 40496-020-00268-0$

32. Compton S, Clark D, Chan S, Kuc I, Wubie B, Levin L. Dental Implants in the Elderly Population: A Long-Term Follow-up. Int J Oral Maxillofac Implants. 2017; 32(1): 164-70. DOI: 10.11607/jomi.5305.

33. Marito P, Pratama S, Utomo HPD, Koesmaningati $\mathrm{H}$, Kusdhany LS. Masticatory ability assessments and related factors. $\mathrm{J}$ Int Dent Med Res. 2018; 11(2): 206-10.

34. César Neto JB, Rosa EF, Pannuti CM, Romito GA. Smoking and periodontal tissues: a review. Braz Oral Res. 2012;26(1):25-31. DOI: 10.1590/s1806-83242012000700005.

35. Feizi A, Keshteli AH, Khazaei S, Adibi P. A new insight into masticatory function and its determinants: a latent class analysis. Community Dent Oral Epidemiol. 2016; 44(1): 46-52. DOI: $10.1111 /$ cdoe. 12189

36. Rech RS, Dos Santos KW, Maahs MAP, Vidor DCGM. Masticatory changes as a result of oral disorders in smokers. Int Arch Otorhinolaryngol. 2014; 18(4): 369-75. DOI: 10.1055/s-0034-1385843

37. Similä T, Auvinen J, Timonen M, Virtanen J. Long-term effects of smoking on tooth loss after cessation among middle-aged Finnish adults: The Northern Finland Birth Cohort 1966 Study. BMC Public Health. 2016; 16(1): 1-8. DOI: $10.1186 / \mathrm{s} 12889-016-3556-1$

38. Dietrich T, Walter C, Oluwagbemigun K, Bergmann $M$, Pischon $T$, Pischon $N$, et al. Smoking, smoking cessation, and risk of tooth loss: The EPIC-Potsdam study. J Dent Res. 2015; 94(10): 1369-75. DOI: 10.1177/0022034515598961.

39. Souto MLS, Rovai ES, Villar CC, Braga MM, Pannuti CM. Effect of smoking cessation on tooth loss: a systematic review with metaanalysis. BMC Oral Health. 2019; 19(1): 245. DOI: $10.1186 / \mathrm{s} 12903-019-0930-2$

40. Agerberg G, Carlsson GE. Chewing ability in relation to dental and general health: Analyses of data obtained from a questionnaire. Acta Odontol Scand. 1981; 39(3): 147-53. DOI: 10.3109/00016358109162273

41. Peyron MA, Woda A, Bourdiol P, Hennequin M. Age-related changes in mastication. J Oral Rehabil. 2017; 44(4): 299-312. DOI: $\underline{10.1111 /}$ joor. 12478.

42. Yoo JJ, Kim DW, Kim MY, Kim YT, Yoon JH. The effect of diabetes on tooth loss caused by periodontal disease: a nationwide population-based cohort study in South Korea. J Periodontol. 2019; 90(6): 576-83. DOI: 10.1002/JPER.18-0480.

43. Haq MW, Tanwir F, Nawaz M, SabaTabassum, Jabar M. Association of systemic diseases on tooth loss and oral health. J Biomed Sci. 2015; 4(1): 1-7.

44. Hildebrandt GH, Loesche WJ, Lin C-F, Bretz WA. Comparison of the number and type of 
dental functional units in geriatric populations with diverse medical backgrounds. J Prosthet Dent. 1995;(3): 253-61. DOI: 10.1016/s00223913(05)80202-1.

45. Norton NS. Netter's Head and Neck Anatomy for Dentistry. $2^{\text {nd }}$ Ed. Philadelpia: Elsevier Saunders; 2012. 326-367 p.

46. Upadhyaya C, Humagain M. The pattern of tooth loss due to dental caries and periodontal disease among patients attending dental department (OPD), Dhulikhel Hospital, Kathmandu University Teaching Hospital
(KUTH), Nepal. Kathmandu Univ Med J. 2009; 7(25): 59-62. DOI: 10.3126/kumj.v7i1.1767.

47. Marquez-Arrico C, Almerich-Silla J, MontielCompany J. Oral health knowledge in relation to educational level in an adult population in Spain. J Clin Exp Dent. 2019; 11(12): e114350. DOI: $10.4317 /$ jced. 56411

48. McQuistan MR, Qasim A, Shao C, StraubMorarend CL, Macek MD. Oral health knowledge among elderly patients. J Am Dent Assoc. 2015; 146(1): 17-26. DOI: 10.1016/j. adaj.2014.10.002 